Article

\title{
Optimising Potato (Solanum tuberosum L.) Cultivation by Selection of Proper Soils
}

\author{
Štefan Koco ${ }^{1,2}$, Jozef Vilček ${ }^{1,2, *}$, Stanislav Torma ${ }^{1}$, Eva Michaeli ${ }^{2}$ and Vladimír Solár ${ }^{2}$ \\ 1 National Agriculture and Food Centre-Soil Science and Conservation Research Institute, 08001 Prešov, \\ Slovakia; stefan.koco@nppc.sk (Š.K.); stanislav.torma@nppc.sk (S.T.) \\ 2 Department of Geography and Applied Geoinformatics, Faculty of Humanities and Natural Sciences, \\ University of Prešov, 08001 Prešov, Slovakia; eva.michaeli@unipo.sk (E.M.); vladimir.solar@unipo.sk (V.S.) \\ * Correspondence: jozef.vilcek@nppc.sk
}

Received: 3 February 2020; Accepted: 16 April 2020; Published: 6 May 2020

\begin{abstract}
This paper presents an attempt to differentiate the Slovak rural landscape with respect to the possibility of effective potato cultivation and to characterise soil parameters of current potato cultivation areas with the aim to increase the sustainability of the potato production. The selection was based on soil climatic, production and economic parameters. By using the GIS tools and existing databases on soil characteristics in Slovakia, maps of soil suitability categories for potato cultivation were generated. In Slovakia, it was found that $12.3 \%$ of farmland is very suitable for potato cultivation and that as much as $43.1 \%$ is not suitable. Later, the specified categories were characterised in detail and specified with respect to geographic, soil, climatic, production and economic parameters. Currently, most potato crops are cultivated on Cambisols (27\%), Chernozems $(20 \%)$ and Fluvisols $(18 \%)$. Loamy soils (content of particles $<0.01 \mathrm{~mm}$ is $30-45 \%$ ), soils without gravel (gravel content in the depth $0.0-0.6 \mathrm{~m}$ is $<10 \%$ ), deep soils $\left(>0.6 \mathrm{~m}\right.$ ) and soil situated on plains (slope $0^{\circ}-3^{\circ}$ ) are dominant in these regions. We suggest that potato cultivation should be concentrated on the most suitable areas, thereby increasing the economic profitability, improving the ecological stability of the country and supporting the sustainability of the agriculture.
\end{abstract}

Keywords: potato cultivation; soil suitability; agricultural landscape categorisation; GIS

\section{Introduction}

The potato comes from South America where, after the Spanish colonization, it was first spread to Europe and later globally. Currently (2017), potato cultivation takes up about 19.3 million hectares, the world global production is 388 million tons and mean hectare yield is on the level of 20.1 tons [1]. Potato consumption is about $35 \mathrm{~kg}$ per capita per year. The trend is that the area decreases whilst the production per hectare increases [2]. With an intensified production, the need for external inputs such as mainly inorganic substances (fertilizers, preservatives) increases, resulting in a less sustainable production. In Slovakia, the situation follows the global trend. The development of potato production areas has steadily decreased (Figure 1). Currently, potato cultivation takes up 8000 hectares compared to 200,000 ha fifty years ago [3]. 


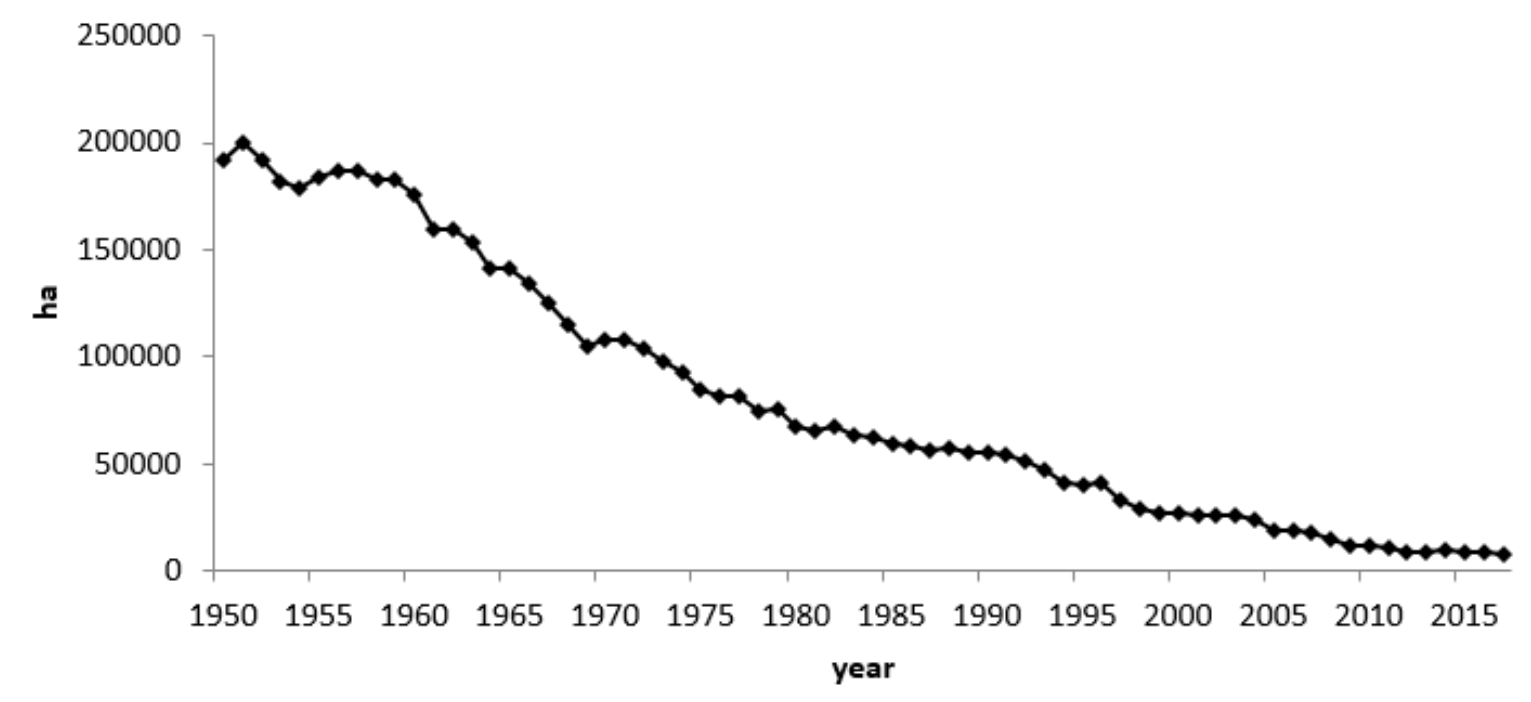

Figure 1. The development of potato cultivation area in Slovakia (1950-2017).

The decreasing trend is a result of changing consumer behaviour usages [4]. While in 1991, the average potato consumption per capita was $90.8 \mathrm{~kg}$, now (2017) it is only $48.9 \mathrm{~kg}$ [5].

Simultaneously, the yields per hectare are gradually increasing following the global tendency, although with variations between individual years. Over the last 66 years, the lowest harvest $\left(5.04 \mathrm{t} \mathrm{ha}^{-1}\right)$ in Slovakia was recorded during 1964 and the highest $\left(20.94 \mathrm{t} \mathrm{ha}^{-1}\right)$ in 2011 . The increased yields per ha have been followed also by a steadily increasing use of pesticides [6]. The highest pesticides consumption is reached in Benelux countries $\left(11.5 \mathrm{~kg} \mathrm{ha}^{-1}\right)$.

The potato is versatile and can be grown in almost any soil type except saline and alkaline soils. Naturally loose soils, which offer little resistance for tuber enlargement, are preferred. Loamy and sandy loam soils rich in organic matter, with good drainage and aeration, are considered the most suitable ones [6]. The ideal soil porosity is about $50 \%$, with a water capacity between $30 \%$ and $40 \%$ (vol.) and an air capacity of about $15 \%$ (vol.). The optimum $\mathrm{pH}$ value for potato cultivation ranges between 4.7 and 6.2, while acidic soil is preferred over alkaline soil. Similar data for another root plants were published by Sikora et al. [7]. Soils originated from weathered granites, flysch sandstones, phyllite and andesite are optimal for potato growing [3].

Given this, our hypothesis is that it will be possible to grow potatoes in a sustainable way by properly matching soil and climatic conditions. Here we present an attempt to select optimal soil and regions for potato cultivation in Slovakia by identifying suitable soils by multicriterial GIS analysis using analytical overlapping of data representing soil properties [8]. The aim of this study is to identify areas (soils) suitable for potato cultivation and those that are not suitable for their cultivation. The objective is also to demonstrate that by choosing suitable areas, it is possible to improve the profit of their cultivation.

\section{Materials and Methods}

An analysis of hectare yields, costs, revenues and profits of chosen farmers in the period 1990-2017 in Slovakia, was executed using data from 120 agricultural farms which cultivated potato and were able to provide us the requested data. In the following, data obtained directly from farmers were assigned to a given point value reflecting the soil production potential of a specific subject (agricultural farm). The point value of soils of individual farms was calculated based on the average of the point values of the occurring soil units. We did not determine the point value of the soil units. This is a parameter that was calculated in our institute by Džatko [9] and is used throughout the whole of society in assessing the quality of soils, economic calculations concerning agricultural soil and also 
legislation in its protection. In view of this, we do not consider it appropriate to change the calculation method. In the calculation, the author proceeded according to the following methodology:

$$
\mathrm{PV}=(\mathrm{ST}+\mathrm{SE}+\mathrm{GD}+\mathrm{ST}) \times \mathrm{TP}
$$

where PV is the point value of the soil units, ST is the point value of soil type (interval 1-60 points), $\mathrm{SE}$ is the point value of slopes and exposure of the landscape (interval 1-15 points), GD is the point value of gravel contents in the soil and soil depth (interval 1-15 points), ST is the point value of soil texture (interval 1-10 points), and TP is the coefficient of the climatic region (interval 1.00-0.59). Based on the mentioned methodology, a map of point values in vector format with the relevant database was prepared for agricultural soils of Slovakia (Figure 2). For the public it is available with orthophotomap background on the soil portal of the Soil Science and Conservation Research Institute in Bratislava (www.podnemapy.sk).

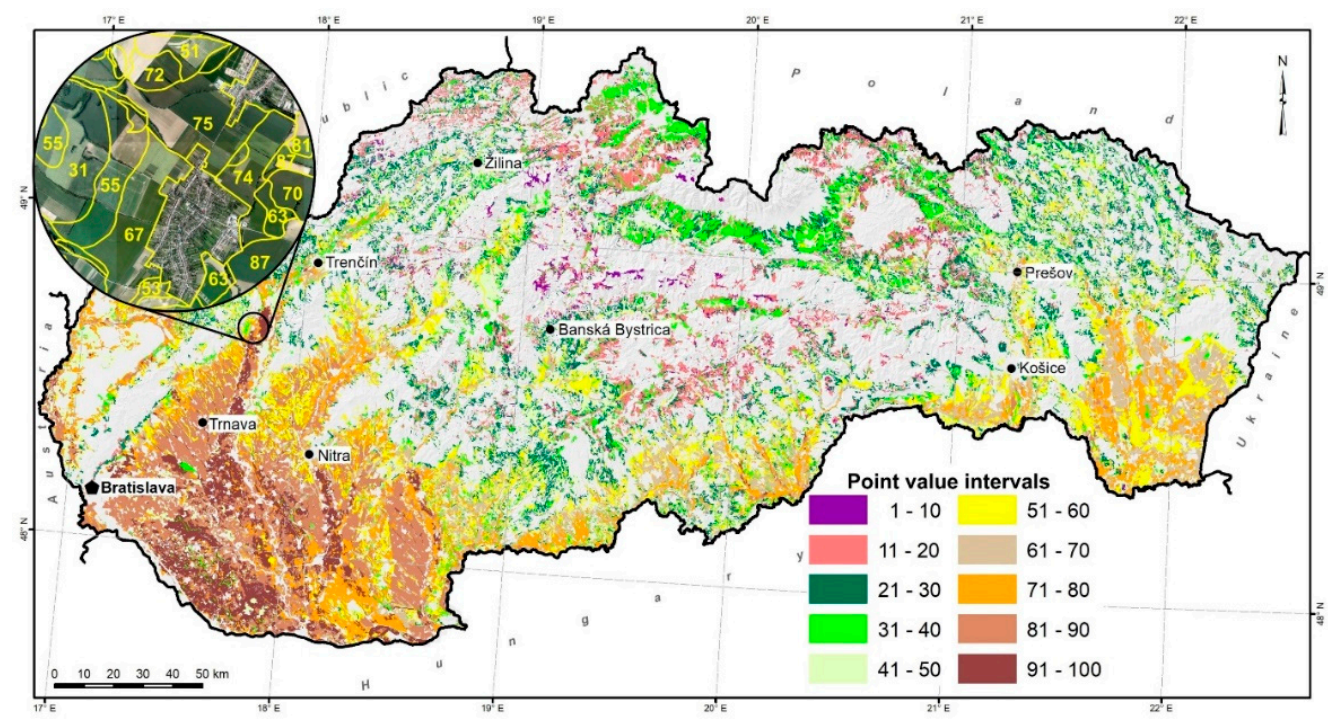

Figure 2. Spatial identification of point values of agricultural soils in Slovakia [9].

The values of the climatic region (TP) were determined according to the long-term average sum of the temperature in respective climatic regions (Table 1).

Table 1. Chosen parameters of soil and climatic regions in Slovakia.

\begin{tabular}{cccccc}
\hline Code & TP & Characteristics & TS $>\mathbf{1 0}{ }^{\circ} \mathbf{C}$ & CMI $(\mathbf{m m})$ & $\mathbf{T ~ V e g e t ~}^{\circ} \mathbf{C}$ \\
\hline 00 & 1.00 & very warm, very dry, flat & $>3000$ & 200 & $16-17$ \\
01 & 0.95 & warm, very dry, flat & $3000-2800$ & $200-150$ & $15-17$ \\
02 & 0.88 & sufficiently warm, dry, hilly & $2800-2500$ & $150-100$ & $15-16$ \\
03 & 0.95 & warm, very dry, flat, continental & $3160-2800$ & $200-150$ & $15-17$ \\
04 & 0.94 & warm, very dry, basin-like, continental & $3030-2800$ & $200-100$ & $15-16$ \\
05 & 0.87 & relatively warm, dry, basin-like, continental & $2800-2500$ & $150-100$ & $14-15$ \\
06 & 0.86 & relatively warm, moderately dry, & $2800-2500$ & $100-50$ & $14-15$ \\
07 & 0.79 & highland-like, continental & $2500-2200$ & $100-0$ & $13-15$ \\
08 & 0.73 & moderately warm, moderately moist & $2200-2000$ & $100-0$ & $12-14$ \\
09 & 0.68 & moderately cold, moderately moist & $2000-1800$ & $60-50$ & $12-13$ \\
10 & 0.59 & cold, moist & $<1800$ & $<50$ & $10-11$ \\
\hline
\end{tabular}

Notes: TP-coefficient for climatic region for soil point value calculation. TS $>10^{\circ} \mathrm{C}$-sum of average daily air temperatures more than $10^{\circ} \mathrm{C}$. CMI $(\mathrm{mm})$-climatic moisture indicator (difference of potential evaporation and precipitation) according to Budyko (Tomlain [10], Škvarenina et al. [11], Džatko and Sobocká [12]). $\mathrm{T}$ veget ${ }^{\circ} \mathrm{C}$-average air temperature during vegetation period. 
To assign potential possible yields of potato for each soil unit (considering the point value) as well as potential economic parameters: costs, sales, yields, regression dependencies of their values obtained from individual farms were used as well as the point values of the soils of these farms.

The specification of soil suitability for potato cultivation (from very suitable to unsuitable) was determined by uniform dividing the point scale of the soil production potential (one-hundred-point scale) into four categories as follows:

1. unsuitable soils: 25 points and less

2. suitable soils: $26-50$ points

3. less suitable soils: $51-75$ points

4. very suitable soils: More than 75 points.

Thereafter, a final map of spatial distribution of particular categories was created by using ArcGIS software based on vector maps in scale of 1:5000, which graphically identify soil point diffusion (Soil Science and Conservation Research Institute database in Bratislava, Slovakia). Analytical overlay of this map layer with layers representing data of soil type, soil texture, climatic region or geomorphological parameters allowed us to create the soil-ecological characteristics of individual categories (regions). Their characteristics are mentioned in the Results and Discussion section. Apart from these, the characteristics of potatoes' cultivation suitability are added with the productive categories of cultivated lands [9] and integrated index of agricultural soils quality of Slovakia [8].

Productive categorisation of cultivated lands (Table 2) divides agricultural soils of Slovakia into types of their rational use (type AL-typical arable lands, type AG—alternative plots, e.g., soils, which can be used as arable land, but, according to their properties, it is preferable to use them as grassland, type GL—typical permanent grassland, while type GL does not occur in potato cultivation).

Table 2. Productive categories of arable soils in Slovakia [9].

\begin{tabular}{ccc}
\hline Code & Characteristics & Point Value * \\
\hline AL1 & the most productive arable soils & $90-100$ \\
AL2 & highly productive arable soils & $81-89$ \\
AL3 & very productive arable soils & $72-80$ \\
AL4 & productive arable soils & $63-71$ \\
AL5 & medium productive arable soils & $54-62$ \\
AL6 & less productive arable soils & $45-53$ \\
AL7 & low productive arable soils & $36-44$ \\
AG1 & moderately productive arable soils & $28-35$ \\
& and very productive grassland \\
AG2 & medium productive arable soils \\
& and medium productive grassland \\
AG3 & low productive arable soils and & $20-27$ \\
& less productive grassland & $<20$ \\
\hline \multicolumn{3}{c}{ Note: ${ }^{*}$ from 100-points scale. }
\end{tabular}

When determining the soil quality index, the methodology according to Vilček and Koco (2018) [8] was used. According to this, the quality of soils is the result of the assessment of their production potential, environmental potential and potential threat (erosion, compaction, organic matter content).

Integrated indices are defined as follows: very high-quality soils-index 1, high-quality soils-index 2, medium-quality soils-index 3, low-quality soils-index 4, very low-quality soils-index 5.

Identification of potato cultivation areas in the years 2011-2015 was processed on the basis of information of farmers who demanded subsidies by means of the LPIS (Land Parcel Identification System). The LPIS is a system based on aerial or satellite photographs recording all agricultural parcels in the member states of the European Union. A unique number is given to each land parcel to provide a unique identification in space and time. We linked the statistical cultivation data with spatial 
data using this unique identification and selected all parcels where potato was cultivated during the 2011-2015 period. Description of soil properties in selected LPIS parcels where potato was cultivated was obtained using analytical overlay with relevant spatial databases and spatial identifications of various soil parameters. These databases for the whole Slovakia territory are managed by the Soil Science and Conservation Research Institute in Bratislava; spatial analysis where performed using ArcGIS 10.3 software environment.

\section{Results and Discussion}

Point values (PV) of production potential of farms that grew potatoes in 1990-2017 were analysed for their correlation in the form of non-linearpolynomial regression in relation to real yields $(\mathrm{Y})$, costs (C), sales (S) and revenues (R) (average value for 1990-2017 per one hectare) of this crop. The following statistical parameters were determined by this way:

$$
\begin{gathered}
P V \leftrightarrow Y: y=0.0021 x^{2}-0.1422 x+14.325(r=0.291, n=120) \\
P V \leftrightarrow C: y=-0.1435 x^{2}+23.122 x+1218.5(r=0.4147, n=109) \\
P V \leftrightarrow S: y=0.014 x^{2}+13.209 x+679.67(r=0.5242, n=110) \\
P V \leftrightarrow R: y=0.1619 x^{2}+15.33 x+883.29(r=0.7533, n=117)
\end{gathered}
$$

where $y$ is yield, cost, sales, revenues, $x$ is the soil point value, $r$ is the coefficient of correlation and $n$ is the number of paired values.

Using the given equations, it is possible to determine its potential production and economic parameters for any soil (whose point value is known). Potential profit values (losses) and profitability rates for potato cultivation were also derived from regression equations related to economic parameters (Figure 3).

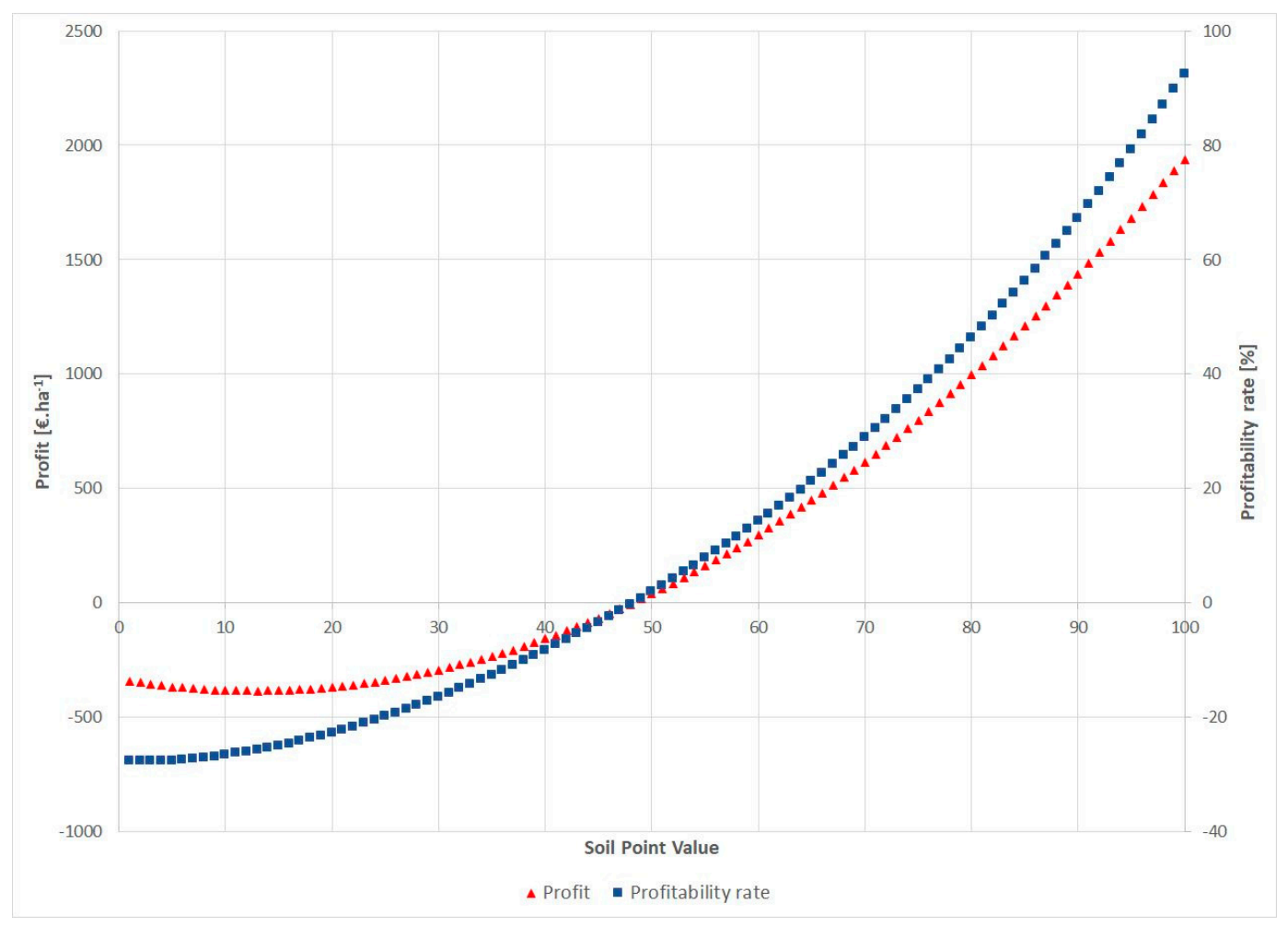

Figure 3. Potential level of profitability and profitability rate of potato cultivation in relation to soil point value. 
The performed analysis shows that in the conditions of Slovakia, potato cultivation is economically profitable in soils with a point value of 48 (zero profitability rate) and more. These are soils which are mostly qualitatively above the average of Slovakia. The average point value of agricultural soils in Slovakia [13] is 53.9 points.

The abovementioned methodological processes and soil data enabled us to create a regionalization of the suitability of soils (rural areas) for growing potatoes in Slovakia. Individual regions are characterized and specified on the basis of production, economic and soil-ecological parameters (Figure 4).

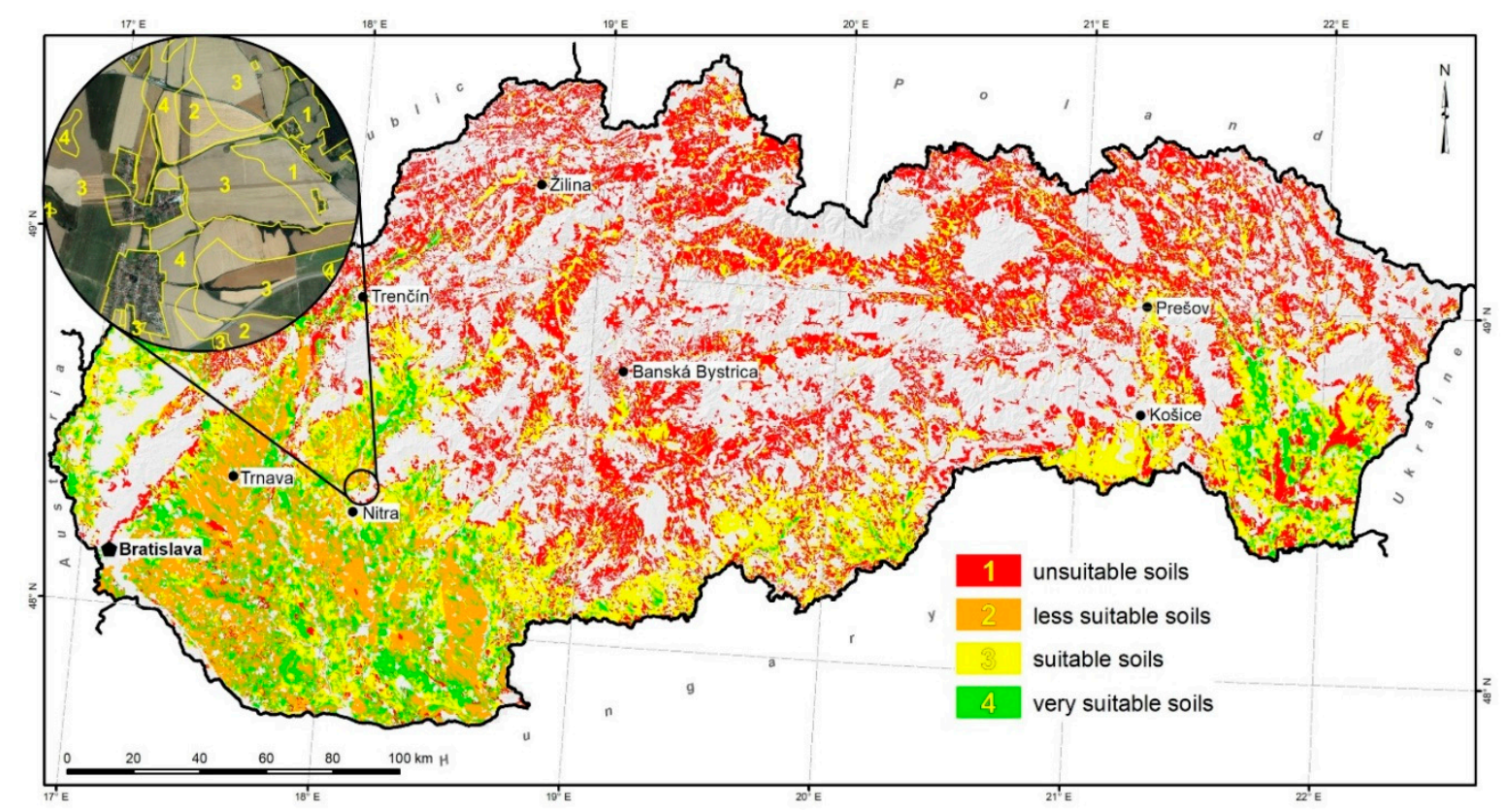

Figure 4. Suitability of agricultural soils in Slovakia for potato cultivation.

The spatial analysis of current potato cultivation areas was created as well.

\subsection{Characteristics of Rural Areas with Regard to Potato Cultivation Suitability}

\subsubsection{Region of Very Suitable Soils}

This region covers about $12.3 \%$ of the agricultural soils in Slovakia. In this region the dominant soil types are Chernozems, Luvisols and Fluvisols, which are moderately heavy, deep and without soil gravel. They can be found in the warm to very warm, dry to very dry climatic regions with a continental climate. Highly productive to productive arable soils were included in this region (76-100 soil points), with a potato production potential greater than 21 tons per hectare and a share of crop rotation on arable soil of up to $7 \%$. According to the production soil categorisation, this region includes the six most productive soil categories (AL1-AL6). It is possible to obtain a profit of over EUR 800 per hectare and a profitability rate of higher than $37 \%$ for potato cultivation. This region is extremely suitable for early and semi-early potato varieties. Agricultural soils evaluated according to five scale index of soil quality [8] reach 1.79 points, which means they belong to the category of very high to high quality soils.

\subsubsection{Region of Suitable Soils}

This region covers about $32.7 \%$ of agricultural soils. The dominant soil types are Cambisols, Fluvisols, Luvisols, Planosols and Regosols, with a soil point value between 51 and 75 points. The soils are mostly moderately heavy to heavy, without soil gravel or slightly gravelly and deep, situated on plains and slight slopes. This area is represented by the climatic regions $05-10$ (relatively warm and dry to very cold and moist). Potato production potential is $15-21$ tons per hectare and its share of crop 
rotation on arable soil should be up to $9 \%$. According to the Slovak production soil categorisation, this area includes very productive arable soils to less productive arable soils (AL3-AL6). It is possible to obtain a profit of EUR $60-800$ per hectare and a profitability rate of $7 \%-37 \%$ for potato cultivation. Agricultural soils evaluated according to five scale index of quality reach 2.14 points, e.g., they belong to the category of high-quality soils.

\subsubsection{Region of Less Suitable Soils}

This region covers about $12.9 \%$ of all agricultural soils, with the dominant soil types Chernozems, Fluvisols and Luvisols, with a soil point value between 26 and 50 points. The soils are moderately heavy, deep, without gravel, and situated on plains. Less suitability for cultivation of potato is a result of the predominance of the very warm and very dry climatic regions $00-01$ that occupy $98 \%$ of the soils. Here, there are moderately heavy, deep soils on variably steep slopes. Potato yields reach $12-15$ tons per hectare. According to the Slovak production soil categorisation, the area includes the medium productive arable soils to poorly productive fields (AL5-AG3). The profit is under EUR 60 per hectare, with a potato cultivation profitability rate of $1 \%$. Agricultural soils evaluated according to five scale index of quality reach 2.83 points, which puts them into the category of medium quality soils.

\subsubsection{Region of Unsuitable Soils}

Soils that are not suitable for potato cultivation make up about $42.1 \%$ of agricultural soils in Slovakia. They occur mostly in the northern and central regions of the country, as well as on heavy to very heavy soils of the Eastern Slovak lowland. From a soil science perspective, there is a great variety of soil types, including light, extremely heavy, acid and loose soils with unfavourable physical and chemical characteristics. Cambizems, Rendzics, Fluvisols and Gleysols are the predominant soil types here. In terms of grain size, moderately heavy, strongly gravelly, shallow soils, occurring on steep and very steep hills, are predominant. The climatic regions $07-10$ are dominant. Potato yields do not exceed 12 tons per hectare in the long term, so it should not occur in the crop rotation. These soils are mostly suitable for permanent grass overgrowth. In terms of economic values, potato cultivation will incur losses in these areas. Agricultural soils evaluated according to five scale index of quality reach 3.65 points, it means they belong to the category of low quality soils. The spatial locations of the above-mentioned regions are presented in Figure 4.

\subsection{Distribution of Potato Cultivation at Present Time}

Due to the biological, but also agronomic requirements of potato, the selection of suitable sites is based on climatic, geomorphological and soil conditions. In terms of climate regionalization of Slovakia, $26 \%$ of the potato cultivation areas are located in a very warm and very dry region. In contrast, almost $14 \%$ of the areas are located in a very cold and wet region.

Most potato crops are cultivated on loam (65\%), clay loam (14\%) and sandy loam (13\%) soils. In terms of soil types, potatoes are most often cultivated on Cambisols $(27 \%)$, Chernozems $(20 \%)$, Fluvisols (18\%) and Dystric Planosols (11\%), mainly in soils without gravel $(62 \%)$ or with little gravel content $(18 \%)$. The soils are predominantly deep $(74 \%)$ on the plains $(55 \%)$ or on slight slopes up to $7^{\circ}$ (28\%). Up to $17 \%$ of the potato areas are located on slopes above $7^{\circ}$, which adversely accelerates water soil erosion.

When comparing the different categories of soil suitability for potato cultivation (potential) with real cultivation areas (Figure 5), 12\% of the selected areas have very good conditions for potato cultivation, $33 \%$ are suitable, $13 \%$ less suitable, and up to $42 \%$ are not suitable for potato cultivation. 


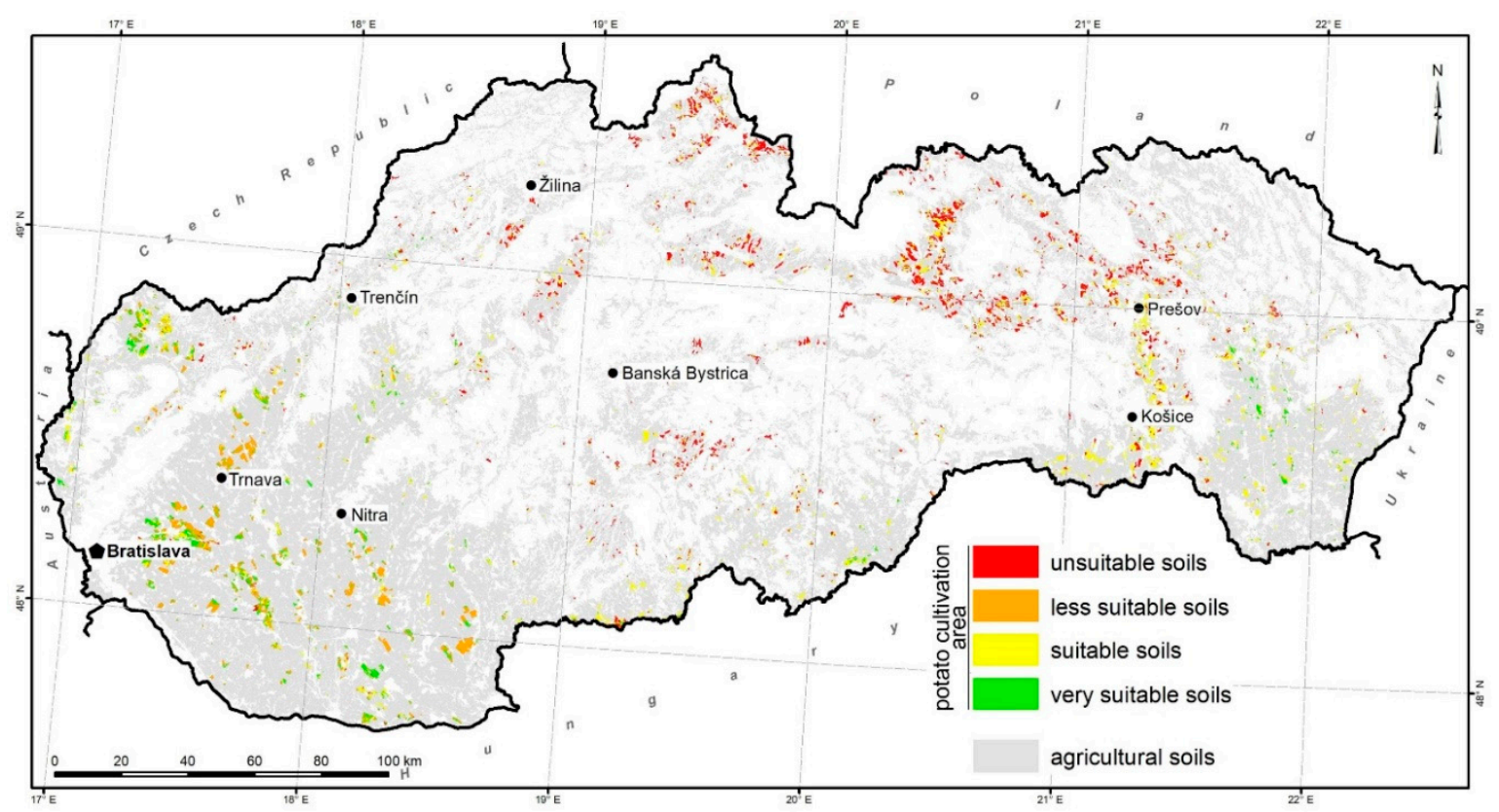

Figure 5. Areas in Slovakia with potato cultivation between 2014-2018 and categorisation their suitability.

A both soil and geographic analysis of the soils unsuitable for potato cultivation where potatoes have been cultivated for the past five years has shown several interesting facts. More than $51 \%$ of these areas are shallow soils (less than $30 \mathrm{~cm}$ ) with high gravel content $(25 \%-50 \%$ of gravel content in topsoil-checked). Up to $41 \%$ of the surfaces are located on slopes above $7^{\circ}$, and up to $68 \%$ are strongly or extremely vulnerable to water erosion. These soil parameters are so limiting from the agronomic and economic point of view for potato cultivation that their location on such areas raises doubts as to whether the farmers have sufficient knowledge of the environmental requirements of the potatoes.

An analysis of various soil parameters on the production capacity of potato under Slovak conditions [3] showed that the yield potential on slight slopes (to $7^{\circ}$ ) was $8.3 \%$ lower, while on moderately steep slopes $\left(7^{\circ}-12^{\circ}\right)$, it was $15.9 \%$ lower when compared with cultivation on plains. Soils with strongly eroded soils obtained $16.6 \%$ lower yields. DeFauw et al. [14] reviewed the effect of erosion on the yield of potato by using GIS tools in Maine (USA). They stated that close to $85 \%$ of potato production soils are classified as either "potentially highly erodible" or "highly erodible" and they required the highest standards in soil conservation practices-which corresponds very closely with our results.

The potential for negative effects on soil quality and erosion at potato cultivation is significant also due to levels of low plant residues input to the soil following potatoes, and the effect of tillage on soil structure, particularly in sandy-textured soils. Similar results have been achieved also by Moulin et al. [15]. Zarzyńska and Pietraszko [16] reported on the impact of unfavourable weather conditions results in greater losses in crop value.

The cultivation of potato on less suitable and unsuitable soils inevitably requires increased input, such as irrigation, erosion protection, fertilisation, etc., which is reflected in the economic outcome.

For potatoes, therefore, it is necessary to choose structural soils with a good stock of organic matter without the threat of water erosion in favourable climatic regions. The organic matter in the soil particularly affects the uptake of important macro and micro-nutrients by potatoes [17-20]. The choice of suitable soils brings not only economic, but also ecological benefits. If potatoes were cultivated only in regions very suitable for this crop (higher yield assumption), it would be possible to decrease the growing area by about 2000 hectares. Reducing pesticide consumption (by about $25 \%$ ) would be another environmental benefit. A good choice of cultivation area of agricultural plants (not only potato) is an ecological stabilizing factor for the agrarian landscape. A similar approach but in other crops 
(winter wheat, sugar beet) in the conditions of Slovakia was presented by Vilček and Torma [21,22]. As in the case of potatoes, they defined the suitable and unsuitable areas for winter wheat and sugar beet cultivation using similar methods and process.

Our results confirm that knowledge of soils (soil science research) and the subsequent correct decision on the locality of cultivation can significantly affect the potato economy and the ecological stability of the landscape (reduction in soil degradation by water erosion). Considering the significant spatial heterogeneity and instability over time, we did not deal with soil chemistry, which could be the subject of further research.

\section{Conclusions}

The natural and soil ecological conditions of Slovakia represent suitable conditions for potato cultivation. However, heterogeneous soil climatic factors do not allow efficient and long-term sustainable cultivation of this crop in all regions. Our results show that:

1. in Slovakia, more than 30 thousand hectares are very suitable for potato cultivation. Rapid reduction in the area of this crop in recent years allows their cultivation in good conditions,

2. in spite of the above, almost $42 \%$ of the potato areas are located in unsuitable territories for this crop (high slope, high gravel content and threat of water erosion),

3. soils with point values more than 48 points are economically profitable for potato cultivation,

4. categorising the suitability of soils for potato cultivation (developed maps and databases) will allow more efficient site selection.

Based on the results of this study, decreased potato cultivation in Slovakia is related to inadequate selection of cultivation sites, resulting in low yields and poor economic profitability. To maintain and intensify potato production in Slovakia, it will be necessary to pay particular attention to the selection of appropriate cultivation areas. Current potato cultivation areas in Slovakia do not guarantee the sustainability of this crop in the long term. We suggest that potato cultivation should be concentrated on the most suitable areas, thereby increasing the economic profitability, improving the ecological stability of the country and supporting the sustainability of the agriculture.

Author Contributions: Conceptualization, J.V.; Data curation, Š.K. and S.T.; Formal analysis, V.S.; Investigation, Š.K. and S.T.; Methodology, J.V. and E.M.; Resources, J.V.; Software, V.S.; Visualization, Š.K.; Writing-original draft, J.V. All authors have read and agreed to the published version of the manuscript.

Funding: This research was funded by the Slovak Research and Development Agency under Grant number APVV-15-0406 and Scientific Grant Agency of Ministry of Education of Slovak Republic under Grant No. VEGA $1 / 0059 / 19$.

Acknowledgments: This work was supported by the Slovak Research and Development Agency under Grant No. APVV-15-0406 and Scientific Grant Agency of Ministry of Education of Slovak Republic under Grant No. VEGA $1 / 0059 / 19$.

Conflicts of Interest: The authors declare no conflict of interest. The funders did not play a role in the design of the study, in the collection, analyses, or interpretation of data, in the writing of the manuscript, or in the decision to publish the results.

\section{References}

1. FAO. 2018 International Year of Potato. Available online: http://www.fao.org/potato-2008/en/potato/ cultivation.html (accessed on 30 March 2017).

2. Deguchi, T.; Iwama, K.; Haverkort, A.J. Actual and Potential Yield Levels of Potato in Different Production Systems of Japan. Potato Res. 2016, 59, 207-225. [CrossRef]

3. Vilček, J.; Bedrna, Z. The Suitability of Agricultural Soils and Landscape in Slovakia for Plant Cultivation; VÚPOP: Bratislava, Slovakia, 2007. (In Slovak)

4. Nagyová, L'.; Dobák, D. A comparison of chosen potato indicators with Eastern and Central Europe countries and the EU. Acta Oecon. Inform. 2004, 1, 8-13. 
5. Jamborová, M. Potato-Situation and Outlook as of June 30, 2018; NPPC VÚEPP: Bratislava, Slovakia, 2018. (In Slovak)

6. Statistical Office of the Slovak Republic. Consumption of Plant Protection Agents. 2018. Available online: http://datacube.statistics.sk/\#!/view/en/VBD_SLOVSTAT/p12022rs/Consumption\%20of\%20plant\% 20protection \%20agents\%20\%5Bp12022rs\%5D (accessed on 20 May 2018).

7. Szelag-Sikora, A.; Sikora, J.; Niemiec, M.; Gródek-Szostak, Z.; Kapusta-Duch, J.; Kuboń, M.; Komorowska, M.; Karcz, J. Impact of Integrated and Conventional Plant Production on Selected Soil Parameters in Carrot Production. Sustainability 2019, 11, 5612. [CrossRef]

8. Vilček, J.; Koco, Š. Integrated index of agricultural soil quality in Slovakia. J. Maps 2018, 14, 68-76. [CrossRef]

9. Džatko, M. Evaluation of Productive Potential of Agricultural Soils and Ecological Regions in Slovakia; VÚPOP: Bratislava, Slovakia, 2002. (In Slovak)

10. Tomlain, J. Climatic moisture indicator. In Atlas SSR; SAV, SÚGK: Bratislava, Slovakia, 1980. (In Slovak)

11. Škvarenina, J.; Križová, E.; Tomlain, J.N. Impact of the climate change on the water balance of altitudinal vegetation stages in Slovakia. Ekologia 2004, 23, 13-29.

12. Džatko, M.; Sobocká, J. The Guidebook for Bonited Soil-Ecological Units Using; VÚPOP: Bratislava, Slovakia, 2009. (In Slovak)

13. Vilček, J. Potential and quality parameters of farmland in Slovakia. Geogr. J. 2011, 63, 133-154.

14. DeFauw, S.; Larkin, R.P.; English, P.J.; Halloran, J.M.; Hoshide, A.K. Geospatial Evaluations of Potato Production Systems in Maine. Am. J. Potato Res. 2012, 89, 471-488. [CrossRef]

15. Moulin, A.P.; Buckley, K.E.; Volkmar, K. Soil quality as affected by amendments in pinto bean-potato rotations. Can. J. Soil Sci. 2011, 91, 533-542. [CrossRef]

16. Zarzyńska, K.; Pietraszko, M. Influence of Climatic Conditions on Development and Yield of Potato Plants Growing Under Organic and Conventional Systems in Poland. Am. J. Potato Res. 2015, 92, 511-517. [CrossRef]

17. Higgs, B.; Johnston, A.E.; Salter, J.L.; Dawson, C.J. Some Aspects of Achieving Sustainable Phosphorus Use in Agriculture. J. Environ. Q. 2000, 17, 80-87. [CrossRef]

18. Kubon, M.; Sporysz, M.; Kocira, S. Use of artificial of clients of organic farms. In Proceedings of the 17th International Multidisciplinary Scientific GeoConference SGEM 2017, Albena, Bulgaria, 29 June-5 July 2017; Volume 17, pp. 1099-1106.

19. Wanli, G.; Hussain, N.; Zongsuo, L.; Dongfeng, Y. Magnesium deficiency in plants: An urgent problem. Crop J. 2016, 4, 83-91.

20. Van Oort, F.; Jongmans, A.G.; Citeau, L.; Lamy, I.; Chevallier, P. Microscale Zn and Pb distribution patterns in subsurface soil horizons: An indication for metal transport dynamics. Eur. J. Soil Sci. 2006, 57, 154-166. [CrossRef]

21. Vilček, J.; Torma, S. Winter wheat (Triticum aestivum L.) growth potential in the Slovak rural landscape. Arch. Agron. Soil Sci. 2016, 62, 235-245. [CrossRef]

22. Vilček, J.; Torma, S. Characterization of Soils in Slovakia for Sugarbeet (Beta vulgaris L.) Cultivation Using Geographic Information system (GIS). Sugar Tech. 2016, 18, 488-492. [CrossRef]

(C) 2020 by the authors. Licensee MDPI, Basel, Switzerland. This article is an open access article distributed under the terms and conditions of the Creative Commons Attribution (CC BY) license (http://creativecommons.org/licenses/by/4.0/). 